\title{
Proceeding Paper \\ Evaluation of the Effect of Extracted Time Conditions on the Phenolic Content of Olive Pastes from $c v$. Arbequina and Discrimination Using a Lab-Made Potentiometric Electronic Tongue ${ }^{+}$
}

\author{
Ítala M. G. Marx ${ }^{1,2, *(\mathbb{D}, \text { Nuno Rodrigues }}{ }^{1}\left(\mathbb{D}\right.$, Ana C. A. Veloso ${ }^{3,4}$, José A. Pereira ${ }^{1}\left(\mathbb{C}\right.$ and António M. Peres ${ }^{1}(\mathbb{D}$ \\ 1 CIMO, Instituto Politécnico de Bragança, 5300-253 Bragança, Portugal; nunorodrigues@ipb.pt (N.R.); \\ jpereira@ipb.pt (J.A.P.); peres@ipb.pt (A.M.P.) \\ 2 LAQV/REQUIMTE, Faculdade de Farmácia da Universidade do Porto, 4050-313 Porto, Portugal \\ 3 Instituto Politécnico de Coimbra, ISEC, DEQB, 3030-199 Coimbra, Portugal; anaveloso@isec.pt \\ 4 CEB-Centre of Biological Engineering, Campus de Gualtar, University of Minho, 4710-057 Braga, Portugal \\ * Correspondence: itala.marx@ipb.pt \\ + Presented at the 1st International Electronic Conference on Chemical Sensors and Analytical Chemistry, \\ 1-15 July 2021; Available online: https:/ / csac2021.sciforum.net/.
}

Citation: Marx, Í.M.G.; Rodrigues, N.; Veloso, A.C.A.; Pereira, J.A.; Peres, A.M. Evaluation of the Effect of Extracted Time Conditions on the Phenolic Content of Olive Pastes from cv. Arbequina and Discrimination Using a Lab-Made Potentiometric Electronic Tongue. Chem. Proc. 2021, 5, 36. https://doi.org/10.3390/ CSAC2021-10556

Academic Editor: Manel del Valle

Published: 1 July 2021

Publisher's Note: MDPI stays neutral with regard to jurisdictional claims in published maps and institutional affiliations.

Copyright: (c) 2021 by the authors. Licensee MDPI, Basel, Switzerland. This article is an open access article distributed under the terms and conditions of the Creative Commons Attribution (CC BY) license (https:/ / creativecommons.org/licenses/by/ $4.0 /)$.

\begin{abstract}
The present study investigated the effect of malaxation times (Mt) (0, 15, 30, 45 and $60 \mathrm{~min})$, during the industrial extraction of $c v$. Arbequina oils at $25^{\circ} \mathrm{C}$ on total phenolic content of olive pastes. Additionally, the possibility of applying a lab-made potentiometric electronic tongue (E-tongue), comprising $40 \mathrm{lipid}$ /polymer sensor membranes with cross sensitivity, to discriminate the olive pastes according to the $\mathrm{Mt}$, was evaluated. The results pointed out that the olive pastes' total phenolic contents significantly decreased ( $p$-value $<0.001$, one-way ANOVA) with the increase of the Mt (from $2.21 \pm 0.02$ to $1.99 \pm 0.03 \mathrm{~g}$ gallic acid equivalents $/ \mathrm{kg}$ olive paste), there being observed a linear decreasing trend $(R$-Pearson $=-0.910)$. These findings may be tentatively attributed to the migration of the phenolic compounds from the olive pastes to the extracted oil and water phases, during the malaxation process. Finally, the E-tongue signals, acquired during the analysis of the olive pastes' methanolic extracts (methanol:water, 80:20 v/v), together with a linear discriminant analysis (LDA), coupled with a simulated annealing (SA) algorithm, allowed us to establish a successful classification model. The E-tongue-LDA-SA model, based on 11 selected non-redundant sensors, allowed us to correctly discriminate all the studied olive pastes according to the Mt (sensitivities of $100 \%$ for training and leave-one-out cross-validation). The satisfactory performance of the E-tongue could be tentatively explained by the known capability of lipid/polymeric sensor membranes to interact with phenolic compounds, through electrostatic interactions and/or hydrogen bonds, which total content depended on the Mt.
\end{abstract}

Keywords: electronic tongue; lipid sensor membranes; chemometrics; olive pastes; total phenolic content

\section{Introduction}

The worldwide consumption of virgin olive oil (VOO) is associated with its appreciated sensory attributes as well as with the recognized health benefits, namely, the reduced risk of chronic diseases and increased longevity, mainly related to the unsaturated fatty acids and minor components like polyphenols [1]. One strategy to ensure the natural enrichment of olive oils in phenolic compounds is based on the optimization of the extraction conditions, namely, using different malaxation times and/or temperatures [2-4].

Several destructive and nondestructive analytical techniques (e.g., chromatography, electrochemical sensor devices and spectroscopy) have been applied to evaluate the olive oil physicochemical and quality characteristics, including the assessment of total and 
individual compositions in phenolics [5,6]. Nevertheless, most of the studies are focused on the olive oil evaluation after being extracted or during the storage period. In those studies, the proposed methodologies were not used as prognostic tools of olive oil quality, i.e., to predict the quality of the olive oil to be processed from measurements on the olive pastes collected during the olive oil extraction process. Actually, a small number of works have been published on the potential prediction of olive oil composition and quality before or during olive oil production $[4,7,8]$. In this context, this study aimed to evaluate the effect of malaxation time (Mt), during the industrial extraction of oils, on the total phenolic content (TPC) of $c v$. Arbequina pastes. Additionally, the use of a potentiometric lab-made electronic tongue (E-tongue) to estimate the TPC in olive pastes collected at different Mt, was also evaluated. This capability could allow establishing indirect correlations between the composition of olive pastes and the TPC of the $c v$. Arbequina oils industrially extracted. It is important to emphasize that E-tongues comprising lipid sensor membranes have been extensively used to determine the phenolic profile and the sensory sensations of olive oils $[3,7]$, which versatility has been related to the low selectivity and cross-sensitivity of the sensors that mimic the behavior of the human biological gustatory receptors [9].

\section{Materials and Methods}

\subsection{Olives and Olive Pastes Samples}

Olives from the $c v$. Arbequina were harvested in mid-November 2017 from an orchard located in Trás-os-Montes region (northeast Portugal). Olive pastes were collected at 5 time-periods $(0,15,30,45$ and $60 \mathrm{~min})$ during the oil extraction at $25^{\circ} \mathrm{C}$, in an industrial olive mill (OLIMONTES, Macedo de Cavaleiros, Portugal. Five samples of olive pastes $(\sim 100 \mathrm{~g})$ were collected from the malaxers during the extraction, totalizing 25 olive paste sub-samples ( 5 replicas $\times 5$ time-periods). The TPC and the potentiometric profiles of the olive pastes were determined.

\subsection{Olive Pastes}

\subsubsection{Analytical Extraction for TPC and Potentiometric Analysis}

The methodology applied was previously described by Marx et al. [6]. The polar extract containing the phenolic compounds was collected to assess the TPC and to establish the potentiometric profiles.

\subsubsection{TPC of Olive Paste Extracts}

The TPC was determined following the methodology proposed by Singleton and Rossi [10] and previous described by Marx et al. [7]. Gallic acid was used as the external standard compound to establish the calibration curve $\left(R^{2}>0.999\right)$, being the results expressed as $\mathrm{g}$ of Gallic acid equivalents (GAE) per $\mathrm{kg}$ of olive paste (g GAE/kg olive paste).

\subsubsection{E-Tongue Apparatus and Potentiometric Analysis of Olive Paste Extracts}

A lab-made potentiometric E-tongue, comprising two cylindrical arrays, was used. Each array contained 20 lipid polymeric cross-sensitive sensor membranes (1st array: S1:1 to S1:20; 2nd array: S2:1 to 2:20). The construction details, as well as the composition of the membranes were previously reported by Marx et al. [3]. The device was connected to an Agilent Data Acquisition unit (model 34970A), which was controlled by an Agilent BenchLink Data Logger software. For the olive pastes analysis, the TPC polar extract was used after a 1:5 $(v / v)$ dilution in deionized water [7]. The diluted solution was analyzed with the E-tongue during $5 \mathrm{~min}$ to allow reaching a pseudo-equilibrium between the non-specific lipid polymeric membranes and the dissolved chemical compounds [7].

\subsection{Statistical Analysis}

The TPC of olive pastes were analyzed using the one-way ANOVA followed by the Tukey's post-hoc multi-comparison test. Linear discriminant analysis (LDA) was applied to evaluate the correct discrimination of the studied pastes based on the best subsets of 
E-tongue sensors selected using the simulated annealing (SA) algorithm. The leave-oneout cross-validation ( $\mathrm{LOO}-\mathrm{CV}$ ) variant was used to evaluate the predictive performance of the classification model and the repeated K-fold-CV. The quality of the results was assessed considering the sensitivity (i.e., the percentage of corrected classified samples). The statistical analysis was performed using the Sub-select and MASS packages of the open-source statistical program R (RStudio version Version 1.2.5033), at a 5\% significance level, as previous detailed by Marx et al. [3,7].

\section{Results and Discussion}

\subsection{TPC of Olive Pastes}

The TPC of the olive pastes, collected at five time-periods $(0,15,30,45$ and $60 \mathrm{~min})$ during the industrial extraction of $c v$. Arbequina oils, were determined following the Folin-Ciocalteau spectrophotometric method and are shown in Table 1. According to the results, the TPC of the pastes linearly decreases with the Mt $(R$-Pearson $=-0.910)$. However, until $30 \mathrm{~min}$ of malaxation, the observed decrease is not significant, there being observed a reduction of $0.46 \%$ between 15 and $30 \mathrm{~min}$. On the other hand, after $30 \mathrm{~min}$ of malaxation, the reduction on the TPC of the studied pastes was more pronounced. Similar trends (negative correlation between the TPC of the olive paste and the Mt) have already been reported in the literature [4]. According to Trapani et al. [4], the decreasing trend was attributed to the enzymatic oxidation of phenolic compounds, probably due to the fact that during the malaxation process the olive paste was exposed to air. The knowledge of the TPC of olive pastes during malaxation could pave the way towards a real-time control of the impact of the $\mathrm{Mt}$ on the olive oils being extracted in order to promote the increase of the total phenolics in olive oils.

Table 1. Statistical analysis of TPC of olive pastes collected at five different malaxation times, during the industrial extraction of olive oil (average, standard deviation, $p$-value and $R$-Pearson).

\begin{tabular}{|c|c|c|c|c|c|c|c|}
\hline \multirow{2}{*}{$\begin{array}{l}\text { Folin-Ciocalteau } \\
\text { Spectrophotometric Method }\end{array}$} & \multicolumn{5}{|c|}{ Malaxation Time } & \multirow{2}{*}{$p$-Value ${ }^{1}$} & \multirow{2}{*}{$R$-Pearson } \\
\hline & $0 \mathrm{~min}$ & $15 \mathrm{~min}$ & $30 \mathrm{~min}$ & $45 \mathrm{~min}$ & $60 \mathrm{~min}$ & & \\
\hline $\begin{array}{c}\text { TPC } \\
\text { (g GAE/kg olive paste) }\end{array}$ & $2.21 \pm 0.02^{\mathrm{A}}$ & $2.18 \pm 0.02^{\mathrm{A}}$ & $2.17 \pm 0.04^{\mathrm{A}}$ & $2.04 \pm 0.03^{\mathrm{B}}$ & $2.00 \pm 0.03^{\mathrm{B}}$ & $<0.0001$ & -0.910 \\
\hline
\end{tabular}

${ }^{1} p$-values for the one-way ANOVA. Different letters in the same row show statistically differences from the given mean $(p<0.05)$. $\mathrm{n}=5$.

\subsection{Estimating TPC of Olive Pastes Based on the Potentiometric E-Tongue Analysis of Olive Paste Extracts}

Among the 40 lipid polymeric sensors, it was possible to establish linear correlations (positive or negative, i.e., signal-on or signal-off) between the potentiometric signals recorded by the E-tongue sensor membranes and the decimal logarithm of TPC, for 75\% of the sensors $\left(0.836 \leq \mathrm{R}^{2} \leq 0.998\right)$. The sensors mean sensitivities varied from +3.7 to $+376 \mathrm{mV} /$ decade, or between -185 to $-42 \mathrm{mV} /$ decade. The linear correlations were obtained for 30 E-tongue sensors (1st array: S1:1, S1:2, S1:3, S4, S1:7, S1:8, S1:10, S1:12, S1:13, S1:15, S1:16, S1:17, S1:18, S1:19 and S1:20; 2nd array: S2:2, S2:3, S2:4, S2:5, S2:7, S2:8, S2:9, S2:10, S2:12, S2:13, S2:15, S2:17, S2:18, S2:19 and S2:20), and the mean TPC calculated by applying the referred linear correlations are shown in Table 2.

Table 2. TPC (mean \pm standard deviation) of olive pastes estimated using the correlations established between the E-tongue signals and the decimal logarithm of TPC, for the five different malaxation times studied (minimum and maximum contents in brackets).

\begin{tabular}{cccccc}
\hline \multirow{2}{*}{ E-Tongue Analysis } & \multicolumn{5}{c}{ Malaxation Time } \\
\cline { 2 - 6 } & $\mathbf{0 ~} \mathbf{~}$ in & $\mathbf{1 5} \mathbf{~} \mathbf{~ i n}$ & $\mathbf{3 0} \mathbf{~}$ in & $\mathbf{4 5} \mathbf{~ m i n}$ & $\mathbf{6 0} \mathbf{~}$ in \\
\hline Estimated TPC & $2.21 \pm 0.03$ & $2.13 \pm 0.04$ & $2.15 \pm 0.03$ & $2.05 \pm 0.02$ & $1.99 \pm 0.01$ \\
(g GAE/kg olive paste) & $(2.06-2.25)$ & $(2.03-2.22)$ & $(2.08-2.23)$ & $(1.99-2.09)$ & $(1.96-2.02)$ \\
\hline
\end{tabular}


The agreement between the experimental TPC (Table 1) and those estimated by the device (Table 2), pointed out that the E-tongue could be applied as a real-time analytical tool to estimate the TPC in olive pastes collected during the oil extraction, allowing establishing the best Mt of the olive pastes that would ensure the extraction of an olive oil rich in phenolic compounds.

Finally, the E-tongue signals acquired during the analysis of the olive pastes' methanolic extracts (methanol: water, 80:20 $\mathrm{v} / \mathrm{v}$ ), allowed the establishing of a successful classification LDA-SA model. The E-tongue-LDA-SA model (Figure 1), based on 11 selected non-redundant sensors, correctly discriminated all the studied olive pastes according to the Mt (sensitivities of $100 \%$ for training and LOO-CV) and $91 \pm 12 \%$ for repeated K-fold-CV. The satisfactory performance of E-tongue could be tentatively attributed by the known capability of the lipid sensor membranes to interact with phenolic compounds, through electrostatic interactions and/or hydrogen bonds, which total content depended on the Mt [7].

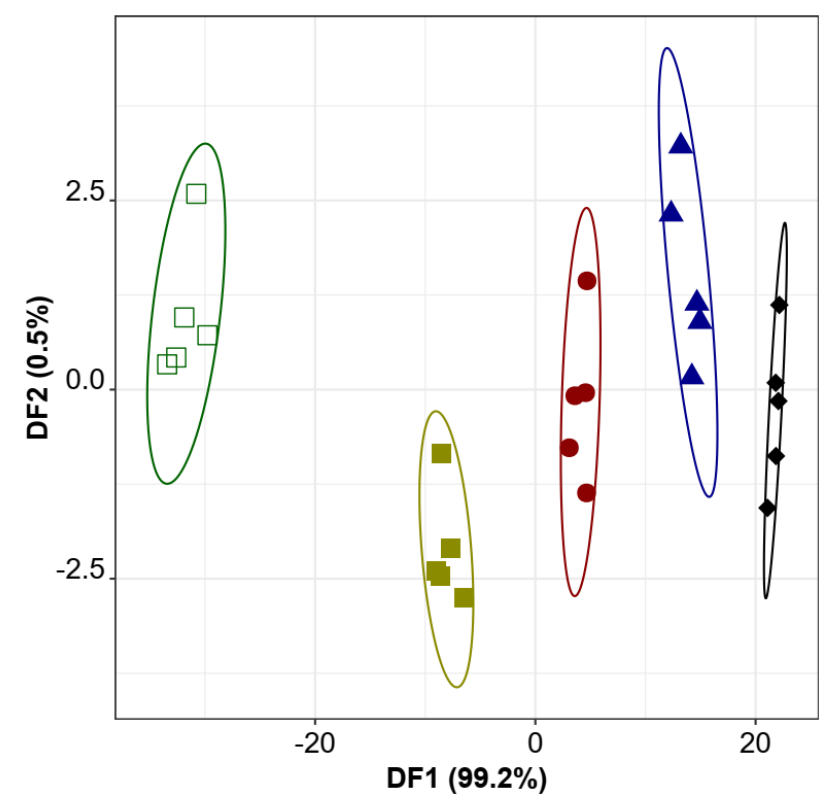

Figure 1. E-tongue-LDA-SA model performance regarding the supervising classification of $c v$. Arbequina olive pastes extracted at $0 \mathrm{~min}(\square) ; 15 \mathrm{~min}(\square) ; 30 \mathrm{~min}(\bullet) ; 45 \mathrm{~min}(\boldsymbol{\Delta})$ and $60 \mathrm{~min}(\bullet)$ based on the potentiometric signals gathered by eleven lipid sensor membranes (1st array: S1:1, S1:8, S1:14, S1:17, S1:18, S1:20; 2nd array: S2:2, S2:3, S2:4, S2:5 and S2:18), selected using the SA algorithm from a set of 40 sensors.

\section{Conclusions}

The spectrophotometric evaluation of the olive pastes showed that until $30 \mathrm{~min}$ of malaxation, the TPC of the olive pastes were not significantly different. Oppositely, after $30 \mathrm{~min}$ of malaxation, the TPC of the pastes decreased, being the lowest contents determined for pastes after $60 \mathrm{~min}$ of malaxation. However, monitoring the TPC of olive pastes by spectrophotometry is a time-consuming task that requires several sample pre-treatments. Furthermore, this conventional spectrophotometric technique has some practical limitations, like the difficult regarding its implementation as an in-situ and online tool, besides being an invasive/destructive technique.

The present study showed that the potentiometric E-tongue analysis of extracts of olive pastes, collected during the industrial extraction of $c v$. Arbequina oils, coupled with chemometric tools, allowed estimating of the TPC. In addition, the E-tongue was capable to correctly discriminate all olive pastes studied according to the malaxation time. 
Taking into account its portability, the lab-made E-tongue could be easily implemented in an industrial olive mill allowing estimating of the TPC of the olive pastes and, indirectly, establishing of the optimal malaxation time of the olive pastes to obtain a high-quality oil.

Supplementary Materials: The following are available online at https:/ / www.mdpi.com/article/ 10.3390/CSAC2021-10556/s1.

Author Contributions: Conceptualization, ÍM.G.M., N.R., J.A.P. and A.M.P.; methodology, Í.M.G.M. and N.R.; software, A.M.P., and A.C.A.V.; validation, J.A.P. and A.M.P.; investigation, I.M.G.M.; resources, Í.M.G.M. and N.R.; writing—original draft preparation, Í.M.G.M.; writing-review and editing, A.M.P. and J.A.P.; supervision, A.M.P.; funding acquisition, I.M.G.M. and N.R. All authors have read and agreed to the published version of the manuscript.

Funding: Foundation for Science and Technology (FCT, Portugal) FCT/MCTES; CIMO (UIDB/00690/ 2020); CEB (UIDB/04469/2020); REQUIMTE-LAQV (UIDB/50006/2020); BioTecNorte operation (NORTE-01-0145-FEDER-000004) funded by the European Regional Development Fund under the scope of Norte2020-Programa Operacional Regional do Norte. Ph.D. research grant (SFRH/BD/ 137283/2018) provided by FCT.

Institutional Review Board Statement: Not applicable.

Informed Consent Statement: Not applicable.

Data Availability Statement: Not applicable.

Acknowledgments: The authors are grateful to the Foundation for Science and Technology (FCT, Portugal) for financial support by national funds FCT/MCTES to CIMO (UIDB/00690/2020), to CEB (UIDB/04469/2020), to REQUIMTE-LAQV (UIDB/50006/2020) and to BioTecNorte operation (NORTE-01-0145-FEDER-000004) funded by the European Regional Development Fund under the scope of Norte2020-Programa Operacional Regional do Norte. Ítala Marx acknowledges the Ph.D. research grant (SFRH/BD/137283/2018) provided by FCT. Nuno Rodrigues thanks the National funding by FCT-Foundation for Science and Technology, P.I., through the institutional scientific employment program contract.

Conflicts of Interest: The authors declare no conflict of interest.

\section{References}

1. Marković, A.K.; Torić, J.; Barbarić, M.; Brala, C.J. Hydroxytyrosol, tyrosol and derivatives and their potential effects on human health. Molecules 2019, 24, 2001. [CrossRef] [PubMed]

2. Guerrini, L.; Masella, P.; Angeloni, G.; Zanoni, B.; Breschi, C.; Calamai, L.; Parenti, A. The effect of an increase in paste temperature between malaxation and centrifugation on olive oil quality and yield: Preliminary results. Ital. J. Food Sci. 2019, 31, 451-458. [CrossRef]

3. Marx, Í.M.G.; Rodrigues, N.; Veloso, A.C.A.; Casal, S.; Pereira, J.A.; Peres, A.M. Effect of malaxation temperature on the physicochemical and sensory quality of $c v$. Cobrançosa olive oil and its evaluation using an electronic tongue. LWT-Food Sci. Technol. 2021, 137, 110426. [CrossRef]

4. Trapani, S.; Breschi, C.; Cecchi, L.; Guerrini, L.; Mulinacci, N.; Parenti, A.; Canutia, V.; Picchia, M.; Caruso, G.; Gucci, R. Indirect indice of oxidative damage to phenolic compounds for the implementation of olive paste malaxation optimization charts. J. Food Eng. 2017, 207, 24-34. [CrossRef]

5. Aleixandre-Tudó, J.L.; Castelló-Cogollos, L.; Aleixandre, J.L.; Aleixandre-Benavent, R. Bibliometric insights into the spectroscopy research field: A food science and technology case study. Appl. Spectrosc. Rev. 2020, 55, 873-906. [CrossRef]

6. Kalogiouri, N.P.; Aalizadeh, R.; Dasenaki, M.E.; Thomaidis, N.S. Application of High Resolution Mass Spectrometric methods coupled with chemometric techniques in olive oil authenticity studies-A review. Anal. Chim. Acta 2020, 1134, 150-173. [CrossRef]

7. Marx, Í.M.G.; Casal, S.; Rodrigues, N.; Veloso, A.C.A.; Pereira, J.A.; Peres, A.M. Estimating hydroxytyrosol-tyrosol derivatives amounts in $c v$. Cobrançosa olive oils based on the electronic tongue analysis of olive paste extracts. LWT-Food Sci. Technol. 2021, 147, 111542. [CrossRef]

8. Martínez-Gila, D.M.; Gámez-García, J.; Bellincontro, A.; Mencarelli, F.; Gómez-Ortega, J. Fast tool based on electronic nose to predict olive fruit quality after harvest. Postharvest Biol. Technol. 2020, 160, 111058. [CrossRef]

9. Wu, X.; Tahara, Y.; Yatabe, R.; Toko, K. Taste sensor: Electronic tongue with lipid membranes. Anal. Sci. 2020, 36, 147-159. [CrossRef] [PubMed]

10. Singleton, V.L.; Rossi, J.A. Colorimetry of total phenolics with phosphomolybdic-phosphotungstic acid reagents. Am. J. Enol. Vitic. 1965, 16, 144-158. 